\title{
The impact of gout as described by patients, using the lens of The International Classification of Functioning, Disability and Health (ICF): a qualitative study
}

Isobel Cairns ${ }^{1}$, Karen Lindsay², Nicola Dalbeth ${ }^{2,3}$, Cesar Díaz-Torné4, Maria Antònia Pou ${ }^{5}$, Basilio Rodríguez Diez Enriqueta Pujol-Ribera ${ }^{7}$, Charlotte Panter ${ }^{8}$, Rob Arbuckle ${ }^{8}$, Sophi Tatlock ${ }^{8}$ and William J. Taylor ${ }^{{ }^{*}}$ (D)

\begin{abstract}
Background: The International Classification of Functioning, Disability and Health (ICF) aims to comprehensively describe the ways in which a person's health condition affects their life. This study aimed to contribute to the development of an ICF core set for gout through patient opinion derived from focus groups and interviews.

Methods: We conducted a secondary qualitative analysis of data from three studies investigating the patient experience of gout. In total there were 30 individual interviews and 2 focus groups $(N=17)$ comprising 47 participants. We conducted thematic analysis of the textual data to extract meaning units, which were then linked to the ICF.

Results: A large number of ICF categories were relevant to patients with gout. Participants mentioned 93 third level categories, 17 of which were mentioned by more than $50 \%$ of patients. The most references for a single category was for b280, Sensation of pain, followed by personal factors (not yet categorised by the ICF). The most participants mentioned the environmental factor e355, Health professional support, followed by 6280, Sensation of pain.

Conclusion: The categories identified in this study as relevant to patients with gout highlight the severe pain associated with this disease, the impact on mobility and corresponding life areas. The roles of health professional support, medication, and personal attitudes to disease management are also reflected in the data. These results will contribute to the development of the ICF core set for gout.
\end{abstract}

Keywords: Gout, International classification of functioning, Disability and health, World Health Organisation, Patient outcome assessment, Qualitative research

\footnotetext{
*Correspondence: will.taylor@otago.ac.nz

${ }^{1}$ Rehabilitation Teaching and Research Unit, Department of Medicine,

University of Otago, PO Box 7343, Wellington, New Zealand

Full list of author information is available at the end of the article
}

(c) The Author(s). 2020 Open Access This article is licensed under a Creative Commons Attribution 4.0 International License, which permits use, sharing, adaptation, distribution and reproduction in any medium or format, as long as you give appropriate credit to the original author(s) and the source, provide a link to the Creative Commons licence, and indicate if changes were made. The images or other third party material in this article are included in the article's Creative Commons licence, unless indicated otherwise in a credit line to the material. If material is not included in the article's Creative Commons licence and your intended use is not permitted by statutory regulation or exceeds the permitted use, you will need to obtain permission directly from the copyright holder. To view a copy of this licence, visit http://creativecommons.org/licenses/by/4.0/. The Creative Commons Public Domain Dedication waiver (http://creativecommons.org/publicdomain/zero/1.0/) applies to the data made available in this article, unless otherwise stated in a credit line to the data. 


\section{Background}

Once known as the 'rich man's disease', gout is increasingly common among older men, where it is the most common inflammatory joint disease [1]. Gout is a metabolic disease caused by high levels of urate, forming crystals that deposit in joints and periarticular tissues, leading to painful and debilitating arthritis [2]. Flares are intermittent but markedly painful, and as the disease progresses may become more frequent and tophi (deposits of monosodium uric acid crystals) may develop [2].

For the sufferer, gout attacks (or 'flares') are not only painful but disabling, leading to a marked decrease in mobility and impacting on many life areas, such as employment [3]. Yet previous means of assessing disability in gout have been problematic because of its episodic nature, and because measures may not adequately reflect the impact of gout on lower limb functioning and mobility or sufficiently capture the breadth of the disease impact as experienced by the patient $[4,5]$.

The International Classification of Functioning, Disability and Health is the World Health Organisation (WHO) framework for the conceptual understanding of health and disability [6]. It classifies the impacts of a disease related to its effect on body functioning, body structures or activities and participation, impacts which may be mediated by the facilitators or barriers offered by a person's physical, social and cultural environment. The complete ICF contains over 1000 fourth level categories [6]. This provides a comprehensive overview of the health of an individual but only some of these will be relevant to a given disease.

The development of ICF core sets is intended to provide a concise set of categories of functioning related to a particular condition, leading to tools for research and practice that have global applicability [7]. Developing these measures requires input from both health professionals and sufferers of the disease. This paper supplements the research of Kool et al. by providing a patient perspective of the impact of gout on various areas of life as described by the ICF [8]. A core-set of ICF categories relevant to people with gout is highly useful to ensure adequate content coverage of tools and instruments to evaluate outcomes, including patient-reported outcomes, in clinical care, intervention studies and other outcomes research.

\section{Methods}

This study was a secondary analysis of data collected by three primary qualitative studies, conducted in the United States [9], New Zealand [10] and Spain (not yet published). These studies are described in more detail below. There were 47 participants in total comprising 30 individual interviews and two focus groups with a total of 17 participants.
This study is a qualitative 'amplified supplementary analysis'; more than one data set has been combined to allow an analysis of an aspect that was partially addressed in the primary studies - namely patient experience of gout - but that supplements these conclusions by including a new factor, the ICF [11]. Each individual study received approval from the relevant research ethics committee or Institutional Review Board.

\section{New Zealand transcripts}

Ten individual interviews with male gout patients were obtained from a study based in South Auckland, NZ [10]. The authors used purposive sampling to ensure a range of ethnicities and experiences, conducting semistructured interviews using a grounded theory methodology to explore participant experiences of gout, their understanding of the disease and attitude toward it and its treatment. Questions were motivated an overall question of "Why is gout so severe in Counties Manukau?" These included questions about the history of the patients' lifetime experience of gout and pre-disease-onset knowledge of gout.

\section{United States transcripts}

Transcripts were obtained from 20 individual interviews with gout patients $($ male $=12$, female $=8$ ) in Baltimore, New Orleans and St. Louis, USA [9]. Sampling was purposive to ensure a range of characteristics, and participants were recruited through their rheumatologist or primary care physician. The main motivation for this study was to understand the patient experience of gout in order to better measure clinical study endpoints or to guide development of a gout-specific outcome measure for clinical trial use. The interviews followed a detailed interview guide; the first half of the interview used openended questions to explore the participant's experience of the disease with a main focus on symptoms and burden, and the second half involved completion and assessment of patient outcome measures, the Heath Assessment Questionnaire - Disability Index and Gout Assessment Questionnaire 'overall concern' domain. Each interview was on average $1.5 \mathrm{~h}$ long.

\section{Spanish transcripts}

Two focus group transcripts were obtained from a study in Barcelona, Spain. The first focus group was purposively sampled to give a range of age, gender and disease characteristics and had 11 participants $(M=8, F=3)$. Participants in the second focus group $(N=6 ; \mathrm{M}=5 \mathrm{~F}=$ 1) were recruited from an outpatient clinic and were selected consecutively. Each focus group lasted about $2 \mathrm{~h}$ and $30 \mathrm{~min}$. Discussion prompts included: what causes gout, how gout was diagnosed, symptoms of gout, effects in daily life, experience of treatments, relationships with 
health professionals, and societal concepts of gout. Focus group discussion was in Castillian and translated into English by a multilingual, native Italian speaker.

\section{Analysis}

Qualitative data analysis followed the process of meaning condensation [12]. Familiarity with the transcripts from each study was established and meaning units were identified in the data [12]. Concepts were identified within each meaning units and were grouped into similar concepts using the analysis software NVivo 11 (NVivo qualitative data analysis Software; QSR International Pty Ltd. Version 11, 2016). For instance, the comment, "You can't walk on it, you know. Even to have $a$ - the sheet on the bed to touch it is painful" contains the concepts 'difficulty walking any distance' and 'pain caused from minimum sensation'. An initial sub-set of 2 transcripts was coded by both coders to establish interrater reliability.

Each concept was then linked to the most appropriate ICF category according to established linking rules [13, 14]. The ICF is divided into chapters, or 'first level' categories, which sub-divide the four separate concepts of body functions, body structures, activities and participation, and environmental factors. Each chapter consists of a number of 'second level' headings, which are made up of 'third level' and then the most detailed 'fourth level' categories (6). Concepts were linked to the most relevant fourth level ICF category if possible. If no such category was appropriate, they were linked to a third level category, or in some instances, a second level category. There were some concepts that were not able to be linked to any ICF categories, which were coded as nondefinable.

As an example, the concept 'difficulty walking any distance' was linked to $d 4508$ Walking, other specified -any distance under the third level category, Walking. 'Pain caused from minimum sensation' was linked to b2702 Sensitivity to pressure, under the third level category, Sensory functions related to temperature and other stimuli. After concepts had been linked to the ICF the second researcher (WT) confirmed the accuracy of linkage decisions in a random subset (10\%) of the linked categories.

\section{Results}

In total 4897 meaning units were identified across all transcripts. These were grouped into 396 initial concepts. These concepts were linked to 93 third level categories of the ICF. Of these, 17 were in the body functions chapter, 5 in the body structures chapter, 35 in the activities and participation chapter, and 34 in the environmental factors chapter, 15 of which denoted facilitators or positive attributes of the environment, and the remaining 19 of which denoted negative attributes or barriers. See Table 1 for a comprehensive overview.

In addition, 27 initial concepts were linked to the concept of personal factors, which are not yet categorised by the ICF. These were grouped into four main areas: individual attitudes to disease and its management (60\% of the references in this category), health literacy (19\%), family experience of gout (12\%) and negative attitudes to seeking care (8\%).

There were several concepts were not definable by the ICF: co-morbidities, association with ethnicity, community visibility of gout, features of onset, physical (nondietary) triggers, and certain approaches to managing pain and disease. Tophi were included as a nondefinable physical factor.

There were 17 categories mentioned by at least $50 \%$ of participants; these categories largely correspond to those that received the greatest number of mentions (Table 2). The top five categories mentioned by the most number of participants were:

e355 Health professionals ++ (98\% of participants), eg BM-02: In - one night, it was so severe, I had to go to the hospital, because I didn't have any medicine. And I went on - went to XXXX Hospital. They gave me three tablets of Cortisine (sic) - Cortisine (sic) - what - how you pronounce it - and told me to go see my regular privatecare physician, which was Dr. XXXX. And she gave me the same thing. And I've been taking it for the last 2 weeks, but I'm kind of over this bout a - at this time.

d570 Looking after one's health -- negative impacts (96\%), eg BM-03: It $g$ - it got - it got a little better, but even though I don't eat the beef, I don't eat the steak, guess what? It just falls on you. Something just - just falls me on you, you know, one way or the other. You know, I think it's just - it's - it's just falls, you know what I'm saying? Because - b280 Sensation of pain (96\%), eg BM04: Because that's what overrides everything else. I mean the swelling is one thing. I mean you can kind of deal with that. The - the - uh, the temp - you know the heating up of the joint, you can kind of deal with that, but the excruciating pain is - you know, dominates all that.

e110 Products or substances for personal consumption - facilitator, and personal factors. Eg SUBJECT: Well he always tells me don't eat this, don't eat that, take these pills because they are the ones and he tried to put me on Allopurinol and they did not work because I was had an attack through it so his only alternative was to give me these pills Colchicine and of course it was down the track through other friends of mine that told me what Prednisone can do to you in the end and it will start eating into your bones or something like that and now I am starting to wake up to that. But at the end of the day it was fixing the pain and it was no fault of his, if I wanted some I was going to have to get some for the pain and all that. 
Table 1 Linked ICF categories and number of references by data source

\begin{tabular}{|c|c|c|c|c|}
\hline ICF Category & US & NZ & Spain & Total \\
\hline \multicolumn{5}{|l|}{ Body functions } \\
\hline b body functions & 4 & 8 & 8 & 20 \\
\hline b126 Temperament and personality functions & 126 & 10 & 6 & 142 \\
\hline b130 Energy and drive functions & 32 & 1 & 0 & 33 \\
\hline b134 Sleep functions & 56 & 0 & 2 & 58 \\
\hline b140 Attention functions & 7 & 1 & 0 & 8 \\
\hline b152 Emotional functions & 117 & 11 & 3 & 131 \\
\hline b180 Experience of self and time functions & 9 & 0 & 0 & 9 \\
\hline b265 Touch function & 22 & 2 & 1 & 25 \\
\hline b270 Sensory functions related to temperature and other stimuli & 81 & 12 & 7 & 100 \\
\hline b280 Sensation of pain & 413 & 40 & 44 & 497 \\
\hline b298 Sensory functions and pain, other specified -- sensation of paralysis & 16 & 0 & 0 & 16 \\
\hline b298 Sensory functions and pain, other specified -- sensation of weakness & 10 & 0 & 0 & 10 \\
\hline b525 Defecation functions & 7 & 5 & 1 & 13 \\
\hline b535 Sensations associated with the digestive system & 2 & 3 & 0 & 5 \\
\hline b710 Mobility of joint functions & 55 & 3 & 7 & 65 \\
\hline b755 Involuntary movement reaction functions & 5 & 0 & 0 & 5 \\
\hline b770 Gait pattern functions & 34 & 4 & 6 & 44 \\
\hline \multicolumn{5}{|l|}{ Activity and participation } \\
\hline $\mathrm{d}$ activities & 37 & 1 & 3 & 41 \\
\hline d230 Carrying out daily routine & 28 & 1 & 0 & 29 \\
\hline d240 Handling stress and other psychological demands & 5 & 2 & 3 & 10 \\
\hline $\begin{array}{l}\text { d298 General tasks and demands, other specified -- planning } \\
\text { to undertake activities }\end{array}$ & 11 & 0 & 0 & 11 \\
\hline d4 mobility & 63 & 5 & 8 & 76 \\
\hline d410 Changing basic body position & 102 & 5 & 0 & 107 \\
\hline d415 Maintaining a body position & 38 & 2 & 1 & 41 \\
\hline d420 Transferring oneself & 28 & 3 & 0 & 31 \\
\hline d430 Lifting and carrying objects & 10 & 0 & 0 & 10 \\
\hline d440 Fine hand use & 35 & 1 & 0 & 36 \\
\hline d445 Hand and arm use & 25 & 1 & 1 & 27 \\
\hline d450 Walking & 148 & 16 & 8 & 172 \\
\hline d455 Moving around & 33 & 3 & 2 & 38 \\
\hline d460 Moving around in different locations & 24 & 5 & 4 & 33 \\
\hline d470 Using transportation & 15 & 2 & 1 & 18 \\
\hline d480 Riding animals for transportation & 0 & 1 & 0 & 1 \\
\hline d510 Washing oneself & 27 & 1 & 2 & 30 \\
\hline d520 Caring for body parts & 21 & 0 & 0 & 21 \\
\hline d530 Toileting & 1 & 0 & 0 & 1 \\
\hline d540 Dressing & 75 & 3 & 3 & 81 \\
\hline d550 Eating & 8 & 0 & 0 & 8 \\
\hline d570 Looking after one's health -- negative impacts & 98 & 74 & 65 & 237 \\
\hline d570 Looking after one's health -- positive impacts & 105 & 59 & 28 & 192 \\
\hline d620 Acquisition of goods and services & 33 & 0 & 0 & 33 \\
\hline d630 Preparing meals & 15 & 0 & 0 & 15 \\
\hline d640 Doing housework & 42 & 0 & 0 & 42 \\
\hline d660 Assisting others & 10 & 0 & 0 & 10 \\
\hline d750 Informal social relationships & 2 & 0 & 2 & 4 \\
\hline
\end{tabular}


Table 1 Linked ICF categories and number of references by data source (Continued)

ICF Category
d760 Family relationships
d770 Intimate relationships
d845 Acquiring, keeping and ter
d850 Remunerative employment
d870 Economic self-sufficiency
d920 Recreation and leisure
d930 Religion and spirituality

\section{Environmental factors}

e110 Products or substances for personal consumption -- barrier e110 Products or substances for personal consumption -- facilitator e115 Products and technology for personal use in daily living e120 Products and technology for personal indoor and outdoor mobility and transportation

e225 Climate

e310 Immediate family --

e310 Immediate family ++

e320 Friends --

e320 Friends ++

e325 Acquaintances, peers, colleagues, neighbours and community members ++

e330 People in positions of authority --

e330 People in positions of authority ++

e355 Health professionals --

e355 Health professionals ++

e355 Health professionals 00

e398 Support and relationships, other specified -- absence due to living alone

e398 Support and relationships, other specified -- burden of care for immediate family

e398 Support and relationships, other specified -- emotional impact for family members

e410 Individual attitudes of immediate family members --

e410 Individual attitudes of immediate family members ++

e420 Individual attitudes of friends ++

e420 Individual attitudes of friends 00

e425 Individual attitudes of acquaintances, peers, colleagues, neighbours and community members --

e430 Individual attitudes of people in positions of authority --

e430 Individual attitudes of people in positions of authority ++

e450 Individual attitudes of health professionals --

e450 Individual attitudes of health professionals ++

e460 Societal attitudes --

e460 Societal attitudes 00 or ++

e465 Social norms, practices and ideologies

e498 Attitudes, other specified -- restauranteurs

e570 Social security services, systems and policies ++

e580 Health services, systems and policies --

e580 Health services, systems and policies ++

\section{Body structures}

s710 Structure of head and neck region

$\begin{array}{ll}\text { US } & \text { NZ } \\ 7 & 8 \\ 3 & 0 \\ 4 & 3 \\ 67 & 22 \\ 1 & 2 \\ 34 & 17 \\ 14 & 0\end{array}$

$\begin{array}{ll}\text { Spain } & \text { Total } \\ 5 & 20 \\ 0 & 3 \\ 1 & 8 \\ 9 & 98 \\ 1 & 4 \\ 12 & 63 \\ 0 & 14\end{array}$

49 
Table 1 Linked ICF categories and number of references by data source (Continued)

\begin{tabular}{|c|c|c|c|c|}
\hline ICF Category & US & NZ & Spain & Total \\
\hline s730 Structure of upper extremity & 27 & 3 & 2 & 32 \\
\hline s750 Structure of lower extremity & 110 & 4 & 8 & 122 \\
\hline $\begin{array}{l}\text { s798 Structures related to movement, other } \\
\text { specified -- unspecified joints }\end{array}$ & 26 & 2 & 1 & 29 \\
\hline s810 Structure of areas of skin & 20 & 2 & 4 & 26 \\
\hline nd-ph -- tophi & 1 & 4 & 11 & 16 \\
\hline personal factors & 189 & 164 & 86 & 436 \\
\hline total & 3071 & 829 & 542 & 4439 \\
\hline
\end{tabular}

Categories from 17 of the 30 first level chapters of the ICF were mentioned by participants (Table 3 ). The Body Structures chapter was the least common, with only $5 \%$ of references coded to categories in this chapter; most of this related to Structures Related to Movement. The other chapters of Body Functions, Activities and
Participation, and Environmental Factors were split roughly evenly, with 30,39 and $26 \%$ of total references respectively (Table 4). In these first level categories, Sensory Functions and Pain was the most common in the category of Body Functions; the majority of this was related to b280 Sensation of pain (77\% of the references

Table 2 Top 20 most mentioned ICF categories (ranked in order of most to fewest mentions)

\begin{tabular}{|c|c|c|c|c|c|c|}
\hline \multirow[t]{2}{*}{ ICF category } & \multicolumn{2}{|l|}{ US $(n=20)$} & \multicolumn{2}{|l|}{$\mathrm{NZ}(N=10)$} & \multirow{2}{*}{$\begin{array}{l}\text { Spain }(n=17) \\
\text { Number of } \\
\text { instances (\% of } \\
\text { participants) }\end{array}$} & \multirow{2}{*}{$\begin{array}{l}\text { Total } \\
\text { number of } \\
\text { instances } \\
\text { (\% of } \\
\text { participants) }\end{array}$} \\
\hline & $\begin{array}{l}\text { Number of } \\
\text { instances (\% of } \\
\text { participants) }\end{array}$ & $\begin{array}{l}\text { Median number } \\
\text { of instances per } \\
\text { participant }\end{array}$ & $\begin{array}{l}\text { Number of } \\
\text { instances ( } \% \text { of } \\
\text { participants) }\end{array}$ & $\begin{array}{l}\text { Median number } \\
\text { of instances per } \\
\text { participant }\end{array}$ & & \\
\hline b280 Sensation of pain & $413(100)$ & 18.5 & $40(100)$ & 4 & $44(88)$ & $497(96)$ \\
\hline Personal factors & $189(100)$ & 6.5 & $164(100)$ & 14 & $86(82)$ & $439(94)$ \\
\hline $\begin{array}{l}\text { e } 110 \text { Products or substances for } \\
\text { personal consumption -- facilitator }\end{array}$ & $170(95)$ & 7 & $42(100)$ & 4.5 & $32(88)$ & $244(94)$ \\
\hline $\begin{array}{l}\text { d570 Looking after one's health -- } \\
\text { negative impacts }\end{array}$ & $98(95)$ & 5 & $74(100)$ & 7 & $65(94)$ & $237(96)$ \\
\hline e355 Health professionals ++ & $92(100)$ & 5 & $78(100)$ & 8 & $51(94)$ & $221(98)$ \\
\hline $\begin{array}{l}\text { d570 Looking after one's health -- } \\
\text { positive impacts }\end{array}$ & $105(85)$ & 5 & $59(100)$ & 3.5 & $28(76)$ & $192(85)$ \\
\hline d450 Walking & $148(100)$ & 7 & $16(80)$ & 1 & $8(29)$ & $172(70)$ \\
\hline $\begin{array}{l}\text { b126 Temperament and personality } \\
\text { functions }\end{array}$ & $126(95)$ & 6.5 & $10(60)$ & 1 & $6(41)$ & $142(68)$ \\
\hline b152 Emotional functions & $117(85)$ & 5.5 & $11(80)$ & 1 & $3(12)$ & $131(57)$ \\
\hline s750 Structure of lower extremity & $110(80)$ & 5.5 & $4(20)$ & 0 & $8(35)$ & $122(51)$ \\
\hline${ }^{a} \mathrm{~d} 410$ Changing basic body position & 102 & & 5 & & 0 & 107 \\
\hline $\begin{array}{l}\text { e110 Products or substances for } \\
\text { personal consumption -- barrier }\end{array}$ & $49(75)$ & 2 & $29(90)$ & 3 & $24(65)$ & $102(74)$ \\
\hline $\begin{array}{l}\text { b270 Sensory functions related to } \\
\text { temperature and other stimuli }\end{array}$ & $81(65)$ & 2.5 & $12(60)$ & 1 & $7(35)$ & $100(53)$ \\
\hline d850 Remunerative employment & $67(80)$ & 2.5 & $22(100)$ & 2 & $9(41)$ & $98(70)$ \\
\hline e310 Immediate family ++ & $61(65)$ & 1 & $26(70)$ & 1 & $8(41)$ & $95(57)$ \\
\hline ad540 Dressing & 75 & & 3 & & 3 & 81 \\
\hline d4 mobility & $63(80)$ & 2 & $5(30)$ & 0 & $8(29)$ & $76(51)$ \\
\hline $\begin{array}{l}\text { a } 120 \text { Products and technology for } \\
\text { personal indoor and outdoor mobility } \\
\text { and transportation }\end{array}$ & 64 & & 3 & & 3 & 70 \\
\hline ab710 Mobility of joint functions & 55 & & 3 & & 7 & 65 \\
\hline d920 Recreation and leisure & $34(70)$ & 2 & $17(60)$ & 1.5 & $12(41)$ & $63(57)$ \\
\hline
\end{tabular}

were mentioned frequently by fewer than $50 \%$ of participants 
Table 3 Most referenced ICF categories by percentage of participants

\begin{tabular}{|c|c|c|c|c|c|}
\hline \multirow[b]{2}{*}{ Name } & \multicolumn{3}{|c|}{ number of participants } & \multirow[b]{2}{*}{ All } & \multirow[b]{2}{*}{ total as $\%$ of total participants } \\
\hline & us $N=20$ & $\mathrm{nz} N=10$ & spain $\mathrm{N}=17$ & & \\
\hline e355 Health professionals ++ & 20 & 10 & 16 & 46 & $98 \%$ \\
\hline d570 Looking after one's health -- negative impacts & 19 & 10 & 16 & 45 & $96 \%$ \\
\hline b280 Sensation of pain & 20 & 10 & 15 & 45 & $96 \%$ \\
\hline e110 Products or substances for personal consumption -- facilitator & 19 & 10 & 15 & 44 & $94 \%$ \\
\hline personal factors & 20 & 10 & 14 & 44 & $94 \%$ \\
\hline d570 Looking after one's health -- positive impacts & 17 & 10 & 13 & 40 & $85 \%$ \\
\hline e110 Products or substances for personal consumption -- barrier & 15 & 9 & 11 & 35 & $74 \%$ \\
\hline d850 Remunerative employment & 16 & 10 & 7 & 33 & $70 \%$ \\
\hline d450 Walking & 20 & 8 & 5 & 33 & $70 \%$ \\
\hline b126 Temperament and personality functions & 19 & 6 & 7 & 32 & $68 \%$ \\
\hline e310 Immediate family ++ & 13 & 7 & 7 & 27 & $57 \%$ \\
\hline d920 Recreation and leisure & 14 & 6 & 7 & 27 & $57 \%$ \\
\hline b152 Emotional functions & 17 & 8 & 2 & 27 & $57 \%$ \\
\hline b270 Sensory functions related to temperature and other stimuli & 13 & 6 & 6 & 25 & $53 \%$ \\
\hline b770 Gait pattern functions & 17 & 3 & 5 & 25 & $53 \%$ \\
\hline s750 Structure of lower extremity & 16 & 2 & 6 & 24 & $51 \%$ \\
\hline d4 mobility & 16 & 3 & 5 & 24 & $51 \%$ \\
\hline d455 Moving around & 19 & 2 & 2 & 23 & $49 \%$ \\
\hline e355 Health professionals -- & 3 & 7 & 12 & 22 & $47 \%$ \\
\hline $\mathrm{d}$ activities & 16 & 1 & 5 & 22 & $47 \%$ \\
\hline
\end{tabular}

for this chapter), followed by Temperament and personality functions (37\%). Mobility and Self-Care were the most common in the category of Activities, with Walking the most common third-level category affected in Mobility (29\%) and d570 Looking after one's health -negative impacts in Self-Care (42\%). In the category of Environmental Factors, Products and Technology and Support and Relationships were the most common chapters, with e110 Products or substances for personal consumption - facilitator as the most common for the first (53\%) and e355 Health professionals ++ as the most common for the second (52\%).

\section{Discussion}

The ICF categories discussed by participants indicate that the most common bodily impacts of gout for patients are related to pain. Body structures most affected were swelling of areas related to movement. Given this, it is not surprising that the activity described most often as compromised was mobility, followed by self-care, but also including major life areas, particularly employment, domestic life and recreation. The impact of pain and limits on activity and mobility lead to impairments in mental and emotional function, as indicated by the number of references to temperament and emotions.
The frequency of references to categories related specifically to looking after one's health under self-care reflects that the discussion of gout frequently touched on what triggered gout flares for participants and how they attempted to manage these triggers. For an individual what triggers a gout flare, such as particular foods, may not be obvious and thus their ability to make healthy choices is compromised. Also, avoiding enjoyed foods because they are triggers may be difficult for patients. The importance of factors related to self-management of the disease is also reflect in the frequency of meaning units coded under the (so far unspecified) 'personal factors' category of the ICF.

Environmental factors were an important feature for participants, both positive and negative - sometimes for the same category. For example, pharmaceutical treatments for gout were a facilitator for many participants but for others medication was ineffective or caused unpleasant side effects. Another factor was the support of health professionals, which could act as a facilitator when it was present, or a barrier when it was not - for example, lack of communication about the importance of managing the disease, or failure to refer on to more specialist care.

There was significant crossover between the frequency of ICF categories across study locations, but also some 
Table 4 Distribution of affected ICF categories

\begin{tabular}{|c|c|c|c|c|c|}
\hline & Num & ff insta & & & $\%$ of total \\
\hline & US & NZ & Spain & All & \\
\hline b1 CHAPTER 1 MENTAL FUNCTIONS & 347 & 23 & 11 & 381 & $10 \%$ \\
\hline b2 CHAPTER 2 SENSORY FUNCTIONS AND PAIN & 542 & 54 & 52 & 648 & $17 \%$ \\
\hline b5 CHAPTER 5 FUNCTIONS OF THE DIGESTIVE, METABOLIC AND ENDOCRINE SYSTEMS & 9 & 8 & 1 & 18 & $0 \%$ \\
\hline b7 CHAPTER 7 NEUROMUSCULOSKELETAL AND MOVEMENT-RELATED FUNCTIONS & 94 & 7 & 13 & 114 & $3 \%$ \\
\hline Total & & & & 1161 & $30 \%$ \\
\hline S7 CHAPTER 7 STRUCTURES RELATED TO MOVEMENT & 164 & 9 & 11 & 184 & $5 \%$ \\
\hline s8 CHAPTER 8 SKIN AND RELATED STRUCTURES & 20 & 2 & 4 & 26 & $1 \%$ \\
\hline Total & & & & 210 & $5 \%$ \\
\hline d2 CHAPTER 2 GENERAL TASKS AND DEMANDS & 44 & 3 & 3 & 50 & $1 \%$ \\
\hline d4 CHAPTER 4 MOBILITY & 521 & 44 & 25 & 590 & $15 \%$ \\
\hline d5 CHAPTER 5 SELF-CARE & 335 & 137 & 98 & 570 & $15 \%$ \\
\hline d6 CHAPTER 6 DOMESTIC LIFE & 100 & 0 & 0 & 100 & $3 \%$ \\
\hline d7 CHAPTER 7 INTERPERSONAL INTERACTIONS AND RELATIONSHIPS & 12 & 8 & 7 & 27 & $1 \%$ \\
\hline d8 CHAPTER 8 MAJOR LIFE AREAS & 72 & 27 & 11 & 110 & $3 \%$ \\
\hline d9 CHAPTER 9 COMMUNITY, SOCIAL AND CIVIC LIFE & 48 & 17 & 12 & 77 & $2 \%$ \\
\hline Total & & & & 1524 & $39 \%$ \\
\hline e1 CHAPTER 1 PRODUCTS AND TECHNOLOGY & 325 & 74 & 61 & 460 & $12 \%$ \\
\hline e3 CHAPTER 3 SUPPORT AND RELATIONSHIPS & 171 & 161 & 92 & 424 & $11 \%$ \\
\hline e4 CHAPTER 4 ATTITUDES & 25 & 57 & 19 & 101 & $3 \%$ \\
\hline e5 CHAPTER 5 SERVICES, SYSTEMS AND POLICIES & 10 & 19 & 14 & 43 & $1 \%$ \\
\hline Total & & & & 1028 & $26 \%$ \\
\hline
\end{tabular}

differences. It is a limitation of the study that such differences cannot be attributed to local culture but may have been influenced by the research protocol used in each location. Yet, the diversity of these patient groups and the large sample size is also one of the strengths of this study.

That this study was a secondary analysis of existing qualitative data is a limitation, as control could not be exercised over the collection of information to cover the ICF comprehensively with each participant. Different research objectives for each study meant that although there was a large quantity of data that was elicited in an unbiased manner, not all of it was relevant to the ICF. There are also issues combining studies with different methodologies - methodology is used to establish rigour and concepts such as 'data saturation', that indicate when the sample size is appropriate for the study. Because this concept was not under our control, the data was possibly 'oversaturated' - leading to excessive mentions of particular concepts while not reflecting the diversity of the experience of gout.

Nearly all the data coding was done by a single observer. This is acknowledged as a significant limitation, as the coding reliability cannot be calculated. However, it did mean that coding was consistent across the 3 data sources.

The concepts elicited from patients in these various studies cohere with previous investigations of the impact of gout on the life of patients, particularly the impact of affected lower limbs on mobility and other activities and taking time off work $(3,4)$. Kool et al. found that outcome studies particularly failed to assess the ICF components of 'Activity and participation' and 'Environmental factors', both of which were found to be particularly relevant to participants in this study (8). The results of this study contribute to the process of developing an ICF Core Set for gout $(7,8)$.

\section{Conclusions}

In this multi-country qualitative study, we found that a large number of ICF categories are relevant to people with gout. Pain and personal factors are the most frequently mentioned ICF categories by people with gout. Environmental factors are also frequently relevant including dietary and other triggers, and the role of health professionals. The results of this study will contribute to the process of developing an ICF Core Set for gout. 
According to the development process recommended by the ICF Research Branch, further research necessary to identify a core-set of ICF categories for gout are: (1) application of the generic ICF Checklist (https://www. who.int/classifications/icf/icfchecklist.pdf?ua $=1$ ) list of categories to patients with gout and (2) a consensus workshop of relevant stakeholders to consider all the data from preceding empirical research and to formulate the final core-set.

\section{Abbreviations}

ICF: The International Classification of Functioning, Disability and Health; NZ: New Zealand; USA: United States of America; WHO: World Health Organisation

\section{Acknowledgements}

Not applicable.

\section{Authors' contributions}

The authors read and approved submission of the final manuscript. IC analysed the data and wrote the first draft of the manuscript. KL and ND conducted the New Zealand data-source study; CDT, MAP, BRD, EPR conducted the Spanish data-source study; CP, RA, ST conducted the US datasource study. WJT conceived the study, obtained funding and contributed to the data analysis and editing of the manuscript.

\section{Authors' information}

Not applicable.

\section{Funding}

This project was supported by Arthritis New Zealand (grant reference R259 to WJT). The US data collection was funded by Pfizer (undertaken commercially by Adelphi Values). The NZ data collection was supported by the Maaori Gout Action Group of Counties Manukau District Health Board and the Auckland Rheumatology Fund (to KL). The Spanish data were collected with the direct support of the authors. The funders had no direct role in the conduct of the reported study, analysis of the data or writing of the manuscript.

\section{Availability of data and materials}

The datasets generated and/or analysed during the current study are not publicly available due to the data consisting of confidential textual transcripts from individual participants.

\section{Ethics approval and consent to participate}

This study reports on a secondary analysis of qualitative data that arose from three individual studies. Each individual study received approval from the relevant research ethics committee or Institutional Review Board. The NZ study was approved by the New Zealand Northern A Health and Disability Ethics Committee (reference NTY/06/12/136/AM03). The US study was approved and overseen by an Independent Review Board in the US (approval codes: ADE1-14-472, ADE2-14-168). The Spanish study was approved by the Ethic Committee of Clinical Investigation of the Fundació de Gestió Sanitaria de I'Hospital de la Santa Creu i Sant Pau (approval number 17/034 (OTROS)). Written informed consent was obtained prior to the collection of any data.

\section{Consent for publication}

Not applicable.

\section{Competing interests}

ND has received consulting fees, speaker fees or grants from Takeda, Ardea, AstraZeneca, Cymabay, Abbvie, and Crealta, outside the submitted work. WT has received consulting fees from Pfizer (NZ) and Janssen-Cilag Pty Ltd., outside the submitted work. CDT has received consulting fees, speaker fees or grants from AstraZeneca and Grünenthal. BRT declares no conflicts of interest. RA, ST and CP are employees of Adelphi Values and as such were contracted by Pfizer to conduct the research; they perform research for many other pharmaceutical companies for payment.

\section{Author details}

${ }^{1}$ Rehabilitation Teaching and Research Unit, Department of Medicine, University of Otago, PO Box 7343, Wellington, New Zealand. ${ }^{2}$ Department of Rheumatology, Auckland City Hospital, Auckland, New Zealand. ${ }^{3}$ Department of Medicine, University of Auckland, Auckland, New Zealand. ${ }^{4}$ Universitat Autònoma de Barcelona. Hospital de la Santa Creu i Sant Pau, Barcelona, Spain. ${ }^{5}$ EAP Encants. Institut Català de la Salut, Barcelona, Spain. ${ }^{6}$ Unitat de Reumatologia. Hospital Vall d'Hebró, Barcelona, Spain. IInstitut Universitari d'Investigació en Atenció Primària, ICS, Barcelona, Spain. ${ }^{8}$ Adelphi Values, Adelphi Mill, Bollington, Cheshire SK10 5JB, UK.

Received: 30 September 2019 Accepted: 19 June 2020

Published online: 12 August 2020

\section{References}

1. Smith EU, Diaz Torne C, Perez Ruiz F, March LM. Epidemiology of gout: an update. Best Pract Res Clin Rheumatol. 2010;24(6):811-27.

2. Taylor WJ, Grainger R. Clinical features of gout. In: Terkeltaub R, editor. Gout and other crystal arthropathies: Philadelphia, PA: Saunders/Elsevier; 2012.

3. Kleinman NL, Brook RA, Patel PA, et al. The impact of gout on work absence and productivity. Value Health. 2007;10(4):231-7.

4. ten Klooster PM, Oude Voshaar MA, Taal E, van de Laar MA. Comparison of measures of functional disability in patients with gout. Rheumatology (Oxford). 2011;50(4):709-13.

5. ten Klooster PM, Vonkeman HE, Voshaar MA, Bode C, van de Laar MA. Experiences of gout-related disability from the patients' perspective: a mixed methods study. Clin Rheumatol. 2014;33(8):1145-54.

6. World Health Organization. International classification of functioning, disability and health: ICF. Geneva: WHO; 2001.

7. Cieza A, Ewert T, Ustun TB, Chatterji S, Kostanjsek N, Stucki G. Development of ICF Core sets for patients with chronic conditions. J Rehabil Med. 2004; 36(44 Suppl):9-11.

8. Kool EM, Nijsten MJ, van Ede AE, Jansen TL, Taylor WJ. Discrepancies in how the impact of gout is assessed in outcomes research compared to how health professionals view the impact of gout, using the lens of the international classification of functioning, health and disability (ICF). Clin Rheumatol. 2016:35(9):2259-68.

9. Tatlock S, Rüdell K, Panter C, et al. What outcomes are important for gout patients? In-depth qualitative research into the gout patient experience to determine optimal endpoints for evaluating therapeutic interventions. Patient. 2017;10(1):65-79.

10. Lindsay K, Gow P, Vanderpyl J, Logo P, Dalbeth N. The experience and impact of living with gout: a study of men with chronic gout using a qualitative grounded theory approach. J Clin Rheumatol. 2011;17(1):1-6.

11. Heaton J. Secondary analysis of qualitative data: an overview. Hist Soc Res. 2008:33(3):33-45.

12. Kvale S. Interviews - an introduction to qualitative research interviewing. California: Sage; 1996.

13. Cieza A, Geyh S, Chatterji S, Kostanjsek N, Ustun B, Stucki G. ICF linking rules: an update based on lessons learned. J Rehabil Med. 2005;37(4):212-8.

14. Cieza A, Fayed N, Bickenbach J, Prodinger B. Refinements of the ICF linking rules to strengthen their potential for establishing comparability of health information. Disabil Rehabil. 2019;41(5):574-83.

\section{Publisher's Note}

Springer Nature remains neutral with regard to jurisdictional claims in published maps and institutional affiliations.

Ready to submit your research? Choose BMC and benefit from:

- fast, convenient online submission

- thorough peer review by experienced researchers in your field

- rapid publication on acceptance

- support for research data, including large and complex data types

- gold Open Access which fosters wider collaboration and increased citations

- maximum visibility for your research: over $100 \mathrm{M}$ website views per year

At $\mathrm{BMC}$, research is always in progress.

Learn more biomedcentral.com/submission 